\title{
SUSTAINABLE ECONOMIC GROWTH
}

\section{Constanța CHIȚIBA ${ }^{1}$, Anca COSTEA-DUNĂRINȚU2}

${ }^{1}$ „Dimitrie Cantemir” Christian University Faculty of International Business and Economics, Bucharest, Romania, ${ }^{1} E-m a i l:$ cchitiba@gmail.com
${ }^{2}$ „Dimitrie Cantemir” Christian University Faculty of International Business and Economics, Bucharest, Romania, ${ }^{2} E-m a i l: \underline{\text { anca.dunarintu@gmail.com }}$

Abstract

Globalization is a current phenomenon of our times, with implications and effects in all fields, representing a key factor of economic growth and development. The environment is also at the forefront of this blurring of boundaries, the economic and not only phenomena wave propagation being manifested at local, regional and global scale more acutely. We cannot talk about globalization and free environment without focusing our attention on economic activity. Ensuring sustainable economic growth is an objective that more countries take it into account in an attempt to reconcile the economic needs with those of the environment.
Keywords

Sustainable development, economic growth, resources, natural capital

JEL Codes: Q01, Q2, Q56

\section{Introduction}

Globalization is a current phenomenon of our times, with implications and effects in all fields, representing a key factor of economic growth and development. The environment is also at the forefront of this blurring of boundaries, the economic and not only phenomena wave propagation being manifested at local, regional and global scale more acutely. We cannot talk about globalization and free environment without focusing our attention on economic activity.

Ensuring sustainable economic growth is an objective that more countries take it into account in an attempt to reconcile the economic needs with those of the environment.

The loss of biodiversity is one of the largest global environmental challenges. The effects of reducing the number of species that inhabit natural ecosystems is not limited to a modification of their functionality, this being propagated throughout the chain of interdependence between people and nature. The way the environmental changes caused by economic activities are manifested, especially those that contribute to loss of biodiversity, degradation of biodiversity that has impact on the economy and human well-being, and proposed solutions to global environmental management believe that there are aspects that allow shaping an adequate conceptual framework of the research.

\section{Sustainable Growth}

A green growth strategy is centered on mutually reinforcing aspects in the economic and environmental policy, taking into account the total value of natural capital as a production factor and its role in growth. It focuses on cost-effective ways to mitigate environmental pressures to make a transition to new models of economic growth that will avoid crossing critical thresholds in terms of the environment locally, regionally and globally.

Unsustainability derived from the upward trend is recorded at the demographic level. Based on this consideration, the demand for food has increased, which prompted in intensive farming of the land that causes adverse effects within the meaning of soil degradation and reduction of forested areas.

True sustainability demands a radically different economics which fully recognizes the processes and limits of the biosphere. It demands recognition of the reality of ecological limits to material growth and the need to live on the interest of the remaining ecological capital. (Rees, 1990)

In general the economic growth and development strategies are built around two main features that are in close interdependence: wasteful and unsustainable.

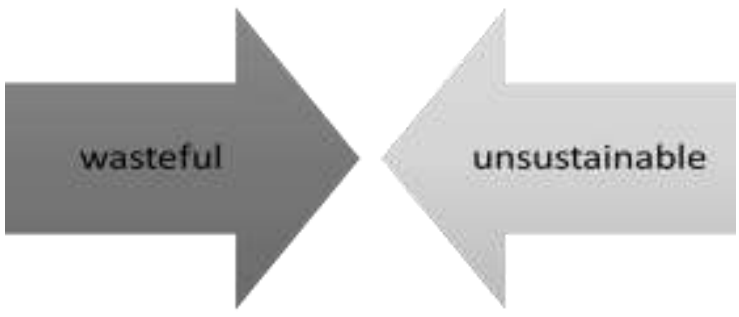

Figure 1. Economic growth and development strategies features 
(Source: own interpretation)

For example, biodiversity is an important contributor to workflows that provide essential water resource for people. There has been recently demonstrated the ability of some ecosystems to provide services as wastewater treatment in better economic efficiency than if they used treatment plants. Filtration and treatment stations for drinking water were exceeded by the stable ecosystems watershed territory in terms of economic efficiency. For example, the water supply of the New York metropolis, with a population of 9 million inhabitants, is achieved by protecting catchment Catskills, avoiding the expense of 6-8 billion for construction and operation of a treatment plant.

The wasteful character in terms of economic growth process reflects on natural capital, acting as a resource for economic activity that is often managed inefficiently.

Production and consumption processes are often wasteful, too. This is particularly evident in the energy sector. Existing energy efficient technologies can be expensive, but is an effective way to reduce energy consumption in new buildings by at least 30 percent. For example, construction of new buildings in terms of energy efficiency could reduce energy costs by more than $50 \%$, while the cost of construction would be increased by only $10 \%$.

Another important issue is the waste originating from the food industry in developing countries, where, because of a well-oiled logistics process, between 15 and $30 \%$ of food is lost before it reaches the market.

In high-income countries, one third of food is wasted by losses in supermarkets and homes.

Sustainable economic growth has the potential to make economic and environmental challenges through the provision of new sources of growth, in line with sustainable development. That potential in highlighted in the figure below.

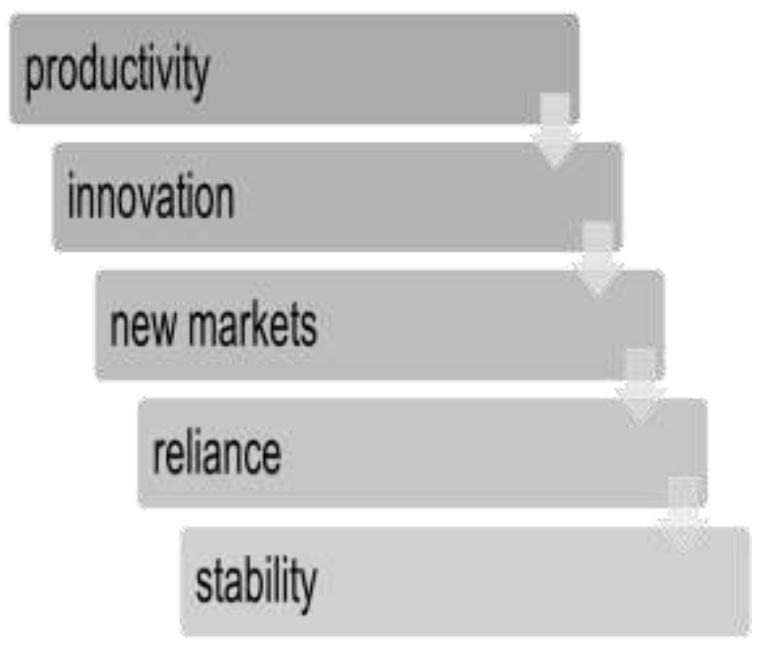

Figure 2. Sustainable economic growth
Source: OECD (2011). Towards Green Growth

Productivity. It refers to incentives provision for greater efficiency in use of resources and natural assets:

- Increasing productivity;

- Reduction of waste;

- Reducing energy consumption;

- To make resources available to the largest usable value.

Innovation. It envisages opportunities for innovation, stimulated by policies and framework conditions that allow new ways to address environmental issues.

New markets. In this case it is about creating new markets and sustaining them through a mobility of workers. The rigidity of the markets has shown to reduce the innovation process (Cotis, de Serres and Duval, 2010). New markets are developed through:

- Stimulate demand for green technologies, goods and services;

- The potential for creating new jobs.

Reliance. Boosting investor confidence through greater predictability and stability in the sense of showing how governments intend to deal with major environmental problems.

Stability. In this respect there are considering a series of measures such as:

- More balanced macroeconomic conditions;

- Reduced volatility of resource prices;

- Supporting fiscal consolidation by reviewing the composition and efficiency of public spending and increase revenue through pollution price.

In the European Union, in accordance with the principles of the Strategy Europe 2020 is a targeted economic growth and development process that aims at achieving three key aspects, namely: (Europa.eu)

$\rightarrow$ smart growth, whose strands promoted are focused on knowledge and innovation, focusing on human resource and focusing on education, research and development and assimilation of new trends in terms of technology and production methods;

$\rightarrow$ inclusive growth, based on supporting job creation, economic, social and territorial cohesion representing a basic pillar in this respect;

$\rightarrow$ sustainable growth, promoting efficiency in all economic, social and environmental issues that can provide a competitive economy in terms of natural resource use. 


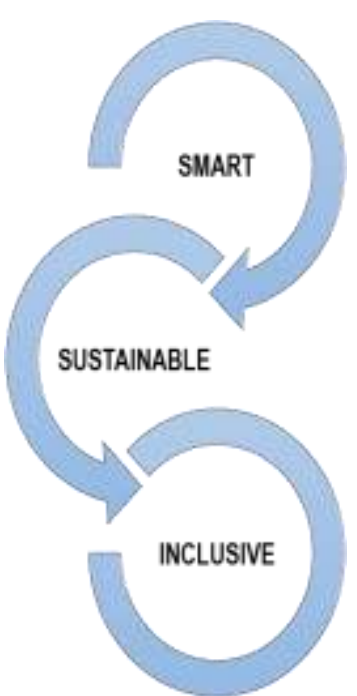

Figure 3. Growth strategy for 2020

(Source: Europa.eu)

\section{Conclusions}

Current patterns of consumption are unsustainable growth and scale required by the current population. Much of this, however, is due to inefficient production and consumption and poor management of natural resources.

Economic activity is affected by environmental influences. Environmental changes are generally assessed as negative, affecting the global ecological balance. Of course, that fact does not exclude the possibility of an interaction with a positive impact. Moreover, concerns increasingly sharper to promote green economy is based on the assumption that there are some economic activities for which environmental balance is positive that positive environmental effects outweigh the negative effects.

\section{References}

Cotis, Jean-Philippe, Alain De Serres, and Romain Duval. "Competitiveness, economic performance and structural policies: An OECD perspective." Dimension of Competitiveness edited by Paul De Grauwe. The MIT Press Cambridge, Massachusetts (2010).

OECD (2011), Towards green growth

Rees, W. E. (1990). The ecology of sustainable development. Ecologist, 20(1), 18-23.

${ }^{* * *}$ Europa.eu 